\title{
Clinical presentation and outcomes of COVID-19 in older hospitalised patients assessed by the record-based multidimensional prognostic index, a cross-sectional study
}

\author{
Ane Borgbjerg Verholt ${ }^{1}$ [ $\cdot$ Merete Gregersen ${ }^{1} \cdot$ Nuria Gonzalez-Bofill $^{2} \cdot$ Troels K. Hansen $^{1} \cdot$ Lotte Ebdrup $^{3}$. \\ Catherine H. Foss ${ }^{1}$ - Lone Winther Lietzen ${ }^{1}$
}

Received: 3 March 2021 / Accepted: 19 May 2021 / Published online: 12 June 2021

(c) European Geriatric Medicine Society 2021

\section{Key summary points}

Aim Confusion was more prevalent in frail than in non-frail older patients at hospital admission.

Finding COVID-19 and accelerated functional decline were associated among frail older hospitalised patients when compared to non-frail.

Message Ninety-day all-cause mortality was 70\% among frail hospitalised patients with COVID-19 and 15\% among non-frail.

\begin{abstract}
Purpose Older people are the most frequently hospital admitted patients with COVID-19. We aimed to describe the clinical presentation of COVID-19 among frail and nonfrail older hospitalised patients and to evaluate the potential association between frailty and clinical course, decision of treatment level with outcomes change in functional capacity and survival.

Methods We performed a multi-center, retrospective cross-sectional cohort study examining data on clinical presentation and frailty-related domains for hospitalised people aged $75+$ years with a positive severe acute respiratory syndrome coronavirus 2 (SARS-CoV-2) test. Frailty was assessed at admission using record-based MPI (rMPI) and Clinical Frailty Scale (CFS). Decision on treatment level about invasive ventilation and cardiopulmonary resuscitation (CPR), change in CFS-score from admission to discharge, changed need of home care, and in-hospital, 30-day and 90-day mortality were registered.

Results 100 patients (median age 82 years (IQR 78-86), 56\% female) with COVID-19 were included. 54 patients were assessed moderately or severely frail (rMPI-score $=2$ or 3 ) and compared to non-frail (rMPI-score $=1$ ). At admission, frail patients presented more frequently with confusion. At discharge, functional decline measured by change in CFS and increased home care was more prevalent among frail than the non-frail. Decisions about no invasive ventilation or CPR were more prevalent among frail older patients with COVID-19 than non-frail. Ninety-day mortality was 70\% among frail patients versus $15 \%$ in non-frail.

Conclusion Frailty seems to be associated with confusion, more frequent decisions about treatment level, larger functional decline at discharge and a higher mortality rate among older patients with COVID-19.
\end{abstract}

Keywords COVID-19 $\cdot$ Frailty $\cdot$ Aged $\cdot$ Cross-sectional study $\cdot$ Geriatrics

Ane Borgbjerg Verholt

anever@rm.dk

1 Department of Geriatrics, Aarhus University Hospital, Palle Juul-Jensens Boulevard 99, 8200 Aarhus, Denmark

2 Department of Internal Medicine, Regional Hospital Viborg, Viborg, Denmark

3 Department of Infectious Diseases, Aarhus University Hospital, Aarhus, Denmark

\section{Background}

Since the outbreak of COVID-19 caused by the Severe Acute Respiratory Syndrome coronavirus 2 (SARS-CoV-2), older people have been the most frequently admitted patients with COVID-19 to hospitals worldwide [1]. High age and frailty are associated with mortality in older COVID-19 inpatients [1-6]. Patients who died from COVID-19 had a higher prevalence of coronary heart disease, hypertension, 
diabetes, malnutrition, multi-medication and functional disabilities [5]. Illness severity is an important marker of risk within the COVID-19 cohort and may be one of the most important prognostic factors [6]. In-hospital mortality rates are found between 27 and $31 \%$ in adults with COVID-19 $[1,4,7]$. Among patients aged 65 or older, the in-hospital mortality rate was $32 \%$ [6], and in frail older patients, up to $65 \%$ died within 30 days [8].

Frailty is defined as reduced physiological reserve and can be used to evaluate older patients in terms of risk of adverse outcomes [9, 10]. Findings of Hewitt et al. show the importance of frailty assessment, rather than age, in combination with other measures in the context of COVID-19 (1). There is no consensus on how to measure frailty. Until now, the validated tool Clinical Frailty Scale (CFS) has been preferred in studies identifying frailty in older patients with COVID-19. It is widely used across specialties and has short time-consumption [1-3, 5, 6, 8, 11, 12]. The CFS was in its origin developed to predict mortality. There is a building evidence worldwide that age, co-morbidity and frailty measured by CFS impact the course of the disease negatively in older patients who have been infected with COVID-19. In the COPE study, $49 \%$ of a cohort of European hospitalized COVID-19 positive adults were defined as frail corresponding to CFS score 5 or more [1]. In the older patients aged 65 years or older, $76-80 \%$ were assessed frail at hospital admission [6, 10]. In geriatric wards, the Multidimensional Prognostic Index (MPI) based on Comprehensive Geriatric Assessment (CGA) [13] is a validated and acknowledged tool $[14,15]$. Since the MPI tool consists of components and several assessment tools, including illness severity, it makes identification of frailty rather time-consuming. However, due to the thorough assessment, the tool is valuable when making decisions about treatment level [15]. During the pandemic, lack of intensive care resources has been debated, highlighting the importance of front-line staff to address this important topic at admission in dialog with patients and relatives.

Frequent clinical manifestations in COVID-19 patients include cough, dyspnea, fever, sore throat, fatigue, myalgia and headache [16]. In addition, some patients may present with diarrhea, vomiting, taste and smell disturbances, and in few cases pleuritic chest pain [6, 16, 17]. Also, there are characteristic changes on chest X-ray, CT scan and in blood test. However, it is well known that older people often have atypical clinical presentation of infectious diseases [18]. So far, the clinical role of frailty among COVID-19-positive older patients is not fully clarified. Therefore, we aimed to describe the clinical presentations of COVID-19 in older inpatients with regard to frailty measured by the recordbased MPI (rMPI) tool [19] and to explore possible associations between frailty level and decision of treatment level, change in physical functional abilities and survival.
Subsequently, the predictive values of rMPI and CFS were compared.

\section{Methods}

\section{Study population and setting}

We undertook a multicenter, retrospective cross-sectional cohort study nested in the Central Denmark Region during the time period between March 1 and May 31, 2020 which equals to the first wave of the pandemic in Denmark. The region consists of 1,3 million inhabitants and approximately $8.5 \%$ of the population are 75 years or older [20]. In Denmark, the healthcare system is tax-funded and all acute admissions take place in public hospitals [21]. Due to a unique and universal identification number (Civil Registration Number, CRN) assigned to all inhabitants in Denmark at birth or immigration, and a region-wide use of electronic health records (EHR), it was possible to follow individual patients across hospital admissions and summarize data about home care needs collected in the municipalities of the region.

We included all patients 75 years and older with a positive SARS-CoV-2 diagnostic test and an admission to one of the seven hospitals treating acute medical conditions in the Central Denmark Region during the study period. We included the positive SARS-CoV-2 diagnostic test results from all test modalities used during the study period verified by oropharyngeal swaps and lower respiratory tract aspirates, knowing that recommendations and test kits changed rapidly during the study period. During the first wave in Denmark, all nursing home residents with positive COVID19 test were admitted to hospital. The Danish health care system never reached a point of where patients were denied admission due to age or frailty, rather the strategy was to admit everyone to isolate in-hospital rather than in, e.g., nursing homes.

\section{Data source}

Relevant CRNs were retrieved from the Central Denmark Region data warehouse that covers all hospitals in the region [22]. We were able to access the EHR and evaluate information about clinical presentation and measurements in the hospital. Also, from the EHR, we retrieved multidisciplinary assessments and information on preadmission cognitive and functional status and care needs generated in the local municipalities and automatically sent to the hospital at admission.

Data were stored in an approved REDCap database at Aarhus University [23]. 


\section{Assessment}

We used the record-based MPI (rMPI) that includes eight domains with weighted scores to assess and divide the patient's frailty level at admission into low as the non-frail patient group, and moderate and severe as the frail group ("Appendix 1") [19, 24]. Furthermore, we used the CFS both at admission and at discharge to describe any functional decline in relation to the hospitalization ("Appendix 2").

The rMPI includes assessment of activities of daily living (ADL), mobility and instrumental ADL (IADL) by Functional Recovery Score, cognitive status by Short Portable Mental Status Questionnaire (SPMSQ), co-morbidity by Cumulated Illness Rating Scale-Geriatrics (CIRS-G), Mini-Nutritional Assessment - short form (MNA-SF), pressure sore risk by Exton Smith Scale (ESS), co-habitation status, and number of prescribed medications. We examined these frailty-related domains and disease characteristics for all included patients by review of the patients' EHR. When rMPI score was equal to one, patients were assessed to be non-frail and when equal to two or three, assessed to be frail.

CFS is a widely used global clinical measure of fitness and frailty that uses pictographs and clinical descriptions to help clinicians stratify older patients on a nine-point scale [25]. CFS scores 1-4 are regarded not frail, whereas scores 5-9 are increasingly frail. CFS was also assessed after thorough review of the EHRs.

Baseline covariates were collected from the EHR in the month leading up to admission and included in the rMPI and CFS, Also, CFS was estimated from descriptions in the EHR at discharge. Further, we identified registered symptoms noted in the EHR at admission, relevant vital measurements and blood tests, and information about decisions on treatment level and life support according to invasive ventilation and cardiopulmonary resuscitation (CPR). The EHR reviews were performed by three specialists in geriatric medicine, who have previously worked with the MPI in a clinical setting. Initially, four EHRs were reviewed by all three specialists to ensure inter-rater reliability. Inconsistencies were identified and debated before further individual assessments were performed.

\section{Statistical methods}

The study presents both descriptive data and associations. Descriptive baseline characteristics for categorical variables were calculated as percentages. Continuous variables were calculated using mean values with standard deviations for normally distributed data, and medians with interquartile range for non-normally distributed data.

Between frail and non-frail patients, continuous variables were compared and analyzed using Student's $t$ test for normally distributed variables and the Wilcoxon rank-sum test for non-normally distributed variables. Categorical variables were analyzed using the Pearson's Chi squared test or Fisher's exact test. Also, a binary linear regression model was used to compare the frail and non-frail patients' clinical presentations. The models were adjusted for age and gender. The association between mortality of frailty was analyzed using a multivariable regression model adjusted for the clinical presentations at admission that were related to 30-day mortality ( $p$ value $<0.08$ ). The regression models were checked by a receiver operating characteristic (ROC) curve.

To compare the discriminative abilities of CFS and rMPI measured at admission, the area under the ROC curve was used to assess the predictive value of 90-day mortality. The ROC curve plots the true-positive rate (sensitivity) against the false-positive rate $(1-$ specificity) at any given cut-off value. An area under the curve (AUC) of 0.5 indicates no discrimination above chance, whereas an AUC of 1.0 indicates perfect discrimination.

A $p$ value $<0.05$ was considered statistically significant. All statistical analyses were performed in STATA version 16 [26].

\section{Results}

The study population included 113 unique individuals with a positive SARS-CoV-2 test and hospital admission in the study period. Thirteen patients were excluded due to lack of relation between positive SARS-CoV-2 test and hospital admission.

\section{At admission}

In Table 1, baseline characteristics including clinical presentations are presented by frailty status. By rMPI rating, $54 \%$ of the patients were identified as frail. The frail patients were five years older than the non-frail $(p=0.001)$. Frail patients had similar symptoms and vital parameters at hospital arrival compared to the non-frail patients with exception of confusion, that was presented in $30 \%$ of the frail and only $13 \%$ of the non-frail patients $(p=0.05)$. Of all the patients with confusion, $63 \%$ were known with cognitive impairment. Mean hemoglobin level was $0.5 \mathrm{mmol} / \mathrm{l}$ lower in the frail patients compared to the non-frail. No other blood test values differed between groups.

\section{Outcomes}

Table 2 shows that registered decisions about treatment level differed between the frail and the non-frail patients. Among frail patients, health care professionals had registered a decision about treatment level in $96 \%$ compared to $56 \%$ among the non-frail patients. Among the frail patients, $87 \%$ had a 
Table 1 Age, sex, social status, vital parameters, blood measurements, symptoms and examinations regarding to frailty status measured by record-based Multidimensional Prognostic Index (rMPI) in patients with COVID-19 and aged $75+$ years

\begin{tabular}{|c|c|c|c|c|c|}
\hline Characteristics & All patients $N=100$ & $\begin{array}{l}\text { Non-frail patients } \\
\text { (rMPI 1) } n=46\end{array}$ & $\begin{array}{l}\text { Frail patients (rMPI } \\
2+3) n=54\end{array}$ & $\begin{array}{l}\text { Relative Risk or coefficient* } \\
(95 \% \mathrm{CI})\end{array}$ & $p$ value \\
\hline Median age, y (IQR) & $82(78-86)$ & $79.5(77-84)$ & $84.5(79-89)$ & $3.57(1.50 ; 5.64)$ & 0.001 \\
\hline Female sex (\%) & 56 & $30(65)$ & $26(48)$ & $1.49(0.93 ; 2.39)$ & 0.10 \\
\hline \multicolumn{6}{|l|}{ Social status (\%) } \\
\hline Living with spouse & 45 & $30(65)$ & $15(28)$ & $0.51(0.32 ; 0.81)$ & 0.005 \\
\hline Institution & 18 & 0 & $18(33)$ & - & NA \\
\hline Living alone & 37 & $16(35)$ & $21(39)$ & $0.97(0.56 ; 1.66)$ & 0.91 \\
\hline \multicolumn{6}{|l|}{ Co-morbidity (\%) } \\
\hline Low & 10 & $10(22)$ & 0 & & \\
\hline Moderate & 43 & $31(67)$ & $12(22)$ & & \\
\hline Severe & 47 & $5(11)$ & $42(78)$ & $7.26(3.12-16.9)$ & $<0.001$ \\
\hline COVID-19 as suspected referral diagnose (\%) & 73 & $34(77)$ & $39(74)$ & $0.95(0.76 ; 1.20)$ & 0.67 \\
\hline \multicolumn{6}{|l|}{ Symptoms (\%) } \\
\hline Fever & 65 & $19(54)$ & $16(46)$ & $0.64(0.36 ; 1,15)$ & 0.14 \\
\hline Cough & 57 & $28(61)$ & $29(54)$ & $1.01(0.75 ; 1.38)$ & 0.93 \\
\hline Dyspnea & 50 & $21(46)$ & $29(54)$ & $1.24(0.82 ; 1.88)$ & 0.31 \\
\hline Chest pain & 9 & $3(7)$ & $6(11)$ & $1.86(0.47 ; 7.31)$ & 0.37 \\
\hline Myalgia & 18 & $12(26)$ & $6(11)$ & $0.60(0.26 ; 1.41)$ & 0.24 \\
\hline Abdominal pain & 38 & $14(30)$ & $24(44)$ & $1.27(0.72 ; 2.23)$ & 0.4 \\
\hline Headache & 9 & $6(13)$ & $3(6)$ & $0.53(0.13 ; 2.05)$ & 0.35 \\
\hline Weakness & 61 & $28(61)$ & $33(61)$ & $0.98(0.70 ; 1.36)$ & 0.89 \\
\hline Changed sense of smell/taste & 0 & 0 & 0 & - & NA \\
\hline Confusion & 22 & $6(13)$ & $16(30)$ & $2.34(1.00 ; 5.51)$ & 0.05 \\
\hline Fall & 15 & $7(15)$ & $8(15)$ & $0.99(0.59 ; 1.65)$ & 0.96 \\
\hline Fatigue & 28 & $15(33)$ & $13(24)$ & $0.82(0.52 ; 1.27)$ & 0.37 \\
\hline Other & 30 & $14(30)$ & $16(30)$ & $0.98(0.66-1.46)$ & 0.93 \\
\hline \multicolumn{6}{|l|}{ Vital parameters, mean (SD) } \\
\hline Respiratory frequency & $23.2(6.4)$ & $22.0(5.9)$ & $24.2(6.7)$ & $1.28(-1.35 ; 3.90)$ & 0.34 \\
\hline Body temperature & $38.1(1.0)$ & $37.9(1.0)$ & $38.1(1.0)$ & $0.22(-0.19 ; 0.64)$ & 0.29 \\
\hline Systolic blood pressure & $135(23)$ & $139(23)$ & $132(23)$ & $-9.06(-18.7 ; 0.62)$ & 0.07 \\
\hline Diastolic blood pressure & $73(18)$ & $79(21)$ & $69(14)$ & $-9.75(-17.2 ;-2.32)$ & 0.01 \\
\hline Pulse & $87(21)$ & $86(22)$ & $88(21)$ & $0.81(-8.14 ; 9.76)$ & 0.86 \\
\hline Saturation without oxygen, $n=69$ & $94(4.1)$ & $94(3.4)$ & $93(4.8)$ & $-1.32(-3.54 ; 0.91)$ & 0.24 \\
\hline Saturation with oxygen, $n=41$ & $95(3.4)$ & $95(2.2)$ & $95(3.9)$ & $-0.18(-2.78 ; 2.42)$ & 0.89 \\
\hline \multicolumn{6}{|l|}{ Blood measurements, mean (SD) } \\
\hline C-reactive protein $[\mathrm{mg} / \mathrm{l}]$ & $79(77.1)$ & $67(61)$ & $90(88)$ & $29(-4.07 ; 61.5)$ & 0.09 \\
\hline Hemoglobin $[\mathrm{mmol} / \mathrm{l}]$ & $7.7(1.3)$ & $8.2(1.2)$ & $7.4(1.2)$ & $-0.69(-1.21 ;-0.18)$ & 0.001 \\
\hline Creatinine $[\mu \mathrm{mol} / 1]$ & $105(51)$ & $93(36)$ & $114(60)$ & $17.2(-4.32 ; 38.8)$ & 0.12 \\
\hline $\mathrm{LDH}[\mathrm{U} / \mathrm{l}] n=89$ & $301(139)$ & $293(102)$ & $308(166)$ & $14.8(-49.0 ; 78.6)$ & 0.65 \\
\hline Alkaline phosphatases [U/l] & $96(65)$ & $87(50.8)$ & $103(74)$ & $14.3(-13.8 ; 42.3)$ & 0.32 \\
\hline Albumin $[\mathrm{g} / \mathrm{l}] n=88$ & $31(4.4)$ & $32(4.0)$ & $31(4.7)$ & $-0.96(-2.94 ; 1.01)$ & 0.34 \\
\hline \multicolumn{6}{|l|}{ Examinations (\%) } \\
\hline Chest X-ray & 86 & $38(84)$ & $48(89)$ & $1.10(0.94 ; 1.28)$ & 0.22 \\
\hline Chest CT-scan & 28 & $16(36)$ & $12(22)$ & $0.58(0.29 ; 1.16)$ & 0.12 \\
\hline Infiltrate verified by $\mathrm{X}$-ray or CT-scan & 78 & $41(89)$ & $37(69)$ & $0.82(0.66 ; 1.00)$ & 0.05 \\
\hline Unilateral & 21 & $13(28)$ & $8(14)$ & $0.67(0.31 ; 1.46)$ & 0.32 \\
\hline Bilateral & 57 & $28(61)$ & $29(54)$ & $0.84(0.58 ; 1.21)$ & 0.35 \\
\hline SARS-CoV-2 verified by swab & 87 & $40(87)$ & $47(87)$ & $0.99(0.86 ; 1.16)$ & 0.98 \\
\hline SARS-CoV-2 verified by tracheal suction & 28 & $13(28)$ & $15(28)$ & $1.15(0.61 ; 2.18)$ & 0.67 \\
\hline CFS up to admission, median (IQR) & $5(3-6)$ & $2.5(2-3)$ & $6(5-7)$ & - & $<0.001$ \\
\hline
\end{tabular}

*Relative risk ratio is used in comparison of dichotomous variables and coefficient is used in continuous and normal distributed variables Adjustment of age and sex are applied in both analysis models. Not normal distributed variables are analyzed with Wilcoxon Rank-sum Test and presented with $\mathrm{p}$ values only

$I Q R$ Interquartile range, SD Standard Deviation, NA Not analysed, CFS Clinical Frailty Score 
Table 2 Outcomes in 75+-year-old patients with COVID-19 according to frailty status measured by record-based Multidimensional Prognostic Index (rMPI)

\begin{tabular}{|c|c|c|c|c|c|}
\hline Characteristics & All patients $N=100$ & $\begin{array}{l}\text { Non-frail patients } \\
\text { (rMPI 1) } n=46\end{array}$ & $\begin{array}{l}\text { Frail patients } \\
\text { (rMPI } 2+3) \\
n=54\end{array}$ & $\begin{array}{l}\text { Relative risk or coef- } \\
\text { ficient* }(95 \% \mathrm{CI})\end{array}$ & $p$ value \\
\hline Decision of treatment level & 77 & $25(56)$ & $52(96)$ & $1.82(1.40 ; 2.36)$ & $<0.001$ \\
\hline Opting out of invasive ventilation & 55 & $8(17)$ & $47(87)$ & $5.09(2.70 ; 9.62)$ & $<0.001$ \\
\hline Opting out of CPR & 58 & $10(22)$ & $48(91)$ & $4.22(2.43 ; 7.33)$ & $<0.001$ \\
\hline \multicolumn{6}{|l|}{ Intensive care } \\
\hline Intensive care unit & 14 & $8(18)$ & $6(11)$ & $0.63(0.23 ; 1.72)$ & 0.37 \\
\hline Non-invasive ventilation & 0 & 0 & 0 & - & NA \\
\hline Invasive ventilation & 12 & $8(17)$ & $4(7)$ & $0.48(0.15 ; 1.55)$ & 0.22 \\
\hline Length of hospital stay, median days (IQR) & $8(3-16)$ & $9(2-17)$ & $7(4-15)$ & - & 0.66 \\
\hline Change* in CFS score, median (IQR) & $2(1-4)$ & $1.5(0-3)$ & $3(1-4)$ & - & 0.02 \\
\hline \multicolumn{6}{|l|}{ Need of increased home care after discharge (\%) } \\
\hline Domestic help & 35 & $19(41)$ & $16(30)$ & $0.70(0.42 ; 1.21)$ & 0.21 \\
\hline Personal help & 31 & $15(33)$ & $16(30)$ & $0.90(0.50 ; 1.64)$ & 0.74 \\
\hline Hospital readmission within 30 days (\%) & 14 & $10(25)$ & $4(18)$ & $0.78(0.25 ; 2.45)$ & 0.67 \\
\hline \multicolumn{6}{|l|}{ Mortality (\%) } \\
\hline In-hospital & 37 & $6(13)$ & $31(57)$ & $4.68(2.16 ; 10.1)$ & $<0.001$ \\
\hline 30-day & 38 & $3(7)$ & $35(65)$ & $10.3(3.41 ; 31.2)$ & $<0.001$ \\
\hline 90-day & 45 & $7(15)$ & $38(70)$ & $4.85(2.41 ; 9.76)$ & $<0.001$ \\
\hline
\end{tabular}

*Relative risk ratio is used in comparison of dichotomous variables and coefficient is used in continuous and normal distributed variables Adjustment of age and gender are applied in both analysis models. Not normal distributed variables are analyzed with Wilcoxon Rank-sum Test and presented with $p$ values only

$I Q R$ Interquartile range, $S D$ Standard Deviation, NA Not analysed, CFS Clinical Frailty Score, CPR Cardiopulmonary Resuscitation

decision of "no critical care" such as invasive ventilation and $91 \%$ had a decision of "no attempt to resuscitation", whereas among the non-frail it was decided in $17 \%$ and $22 \%$, respectively. Median length of hospital stay was 8 days with no difference between groups.

The difference between the CFS score at admission and at discharge showed that frail patients had a more pronounced decline in functional capacity than non-frail patients. The loss of functional capacity was followed by an increased need for domestic and personal help after discharge.

In-hospital mortality was significantly higher in the frail patients ( $57 \%$ vs. $13 \%), p<0.001$. All-cause 30 -day mortality rate was $65 \%$ in the frail group versus $7 \%$ in the non-frail groups, and 90 -day mortality was $70 \%$ among the frail patients and $15 \%$ in the non-frail group $(p<0.001)$. At admission, data showed that temperature above $37.5^{\circ} \mathrm{C}$, tachypnea ( $>20$ breaths per minute) and systolic blood pressure below $140 \mathrm{mmHg}$ were associated with 30-day mortality; and creatinine more than $100 \mu \mathrm{mol} / \mathrm{l}$ was non-significantly associated with 30-day mortality (Fig. 1). The relative risk of 90-day mortality in the frail patients was 4.85 (95\% CI: 2.41-9.76), $p<0.001)$. None of the mortality-related clinical presentations added higher or lower risk of death to the model. Adjustment for confusion did not alter the risk of 90-day mortality ( $\mathrm{RR}=0.97$ (95\% CI: $0.67-1.42), p=0.89$ ). No difference was found in unplanned 30-day readmission rate according to frailty.

\section{rMPI versus CFS}

Figure 2 illustrates equality of the predictive values of rMPI and CFS measured at admission. Both of the frailty tools were capable of predicting 90-day mortality.

\section{Discussion}

\section{Clinical presentation}

The most frequent clinical presentations of COVID-19 in the $75+$-year-old patients were fever, weakness, coughs and dyspnea. Frailty among these patients seems to have a minor impact on the clinical presentation at admission. However, confusion was more prevalent in the frail compared to the non-frail, and short-term mortality was significantly more present in the frail patients.

In an American study, 28\% of older patients admitted to an emergency department (ED) with COVID-19 had 


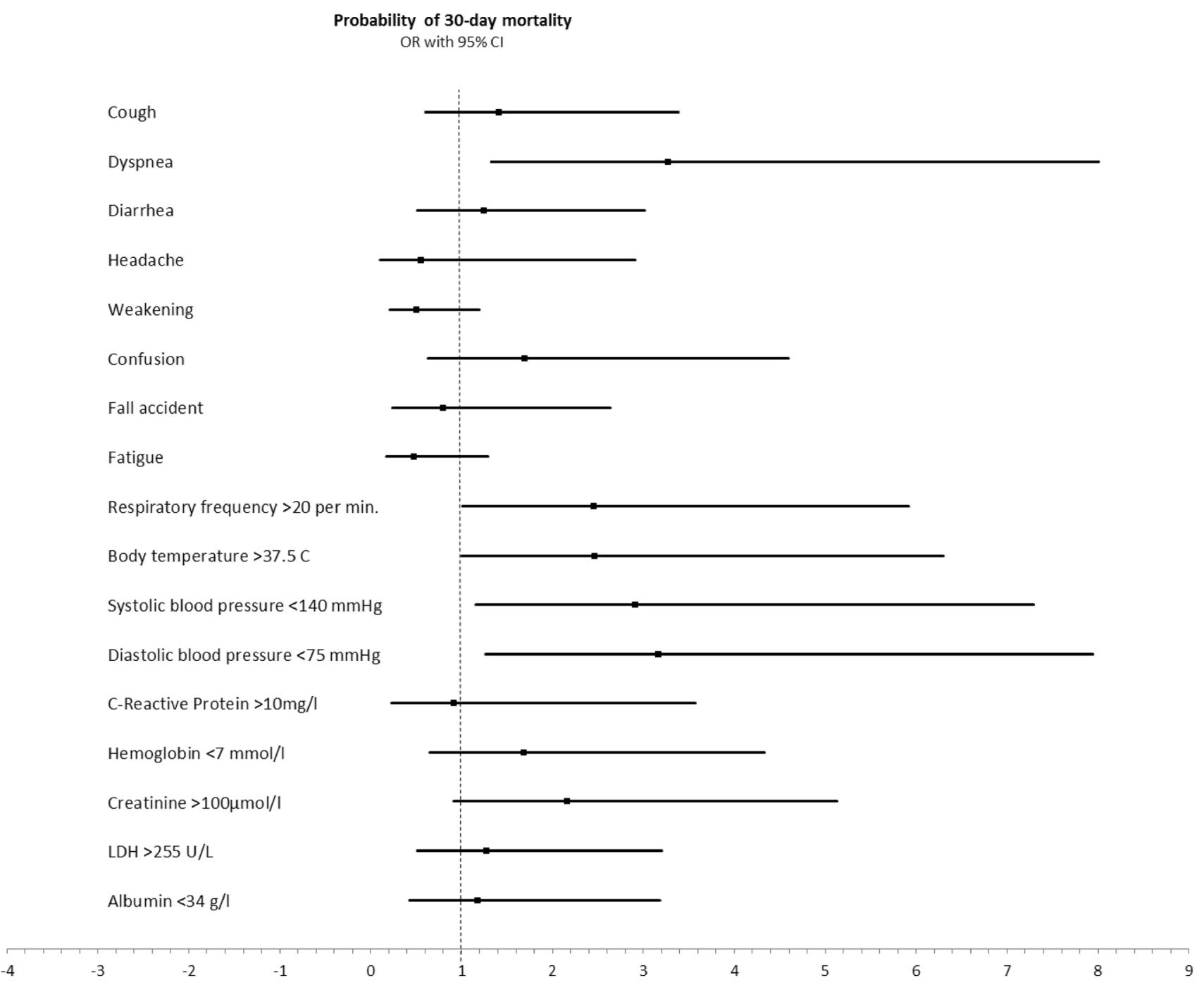

Fig. 1 Prediction of 30-day mortality according to clinical presentations at admission

delirium at presentation [27]. Marengoni et al. found that $27.5 \%$ of patients admitted with COVID-19 to an acute geriatric ward in Italy had delirium at hospital admittance [28] which corresponds to the incidence in a Danish study of $80+$-year-old patients with COVID-19 [29]. However, Vrillon et al. found an even higher incidence of confusion/ delirium by $71 \%$ in patients with COVID- 19 aged 85 years or more [30]. Also, the Italian group found that patients with delirium compared to patients with no delirium were four times more likely to die during their hospital stay than those without. The seriousness of delirium during admission for COVID-19 has been investigated in a Brazilian study, where delirium was independently associated with in-hospital death, increased length of stay, and admission to intensive care in older adults [31]. Patients with both frailty and confusion often have a history of known cognitive impairment [32] and we found such an association.
Similar to our findings, Karlsson et al. found that most patients displayed classical symptoms of COVID-19: fever, cough, respiratory distress, and fatigue [29]. Lui et al. found fever to be less frequent (78\%) among older patients aged 60 years or more compared to younger patients [33], which is consistent with our study where only $65 \%$ had fever at admission. We found a tendency towards a lower incidence of fever in the frail patients compared to the non-frail.

Since falls are an important predictor of negative health outcome among older patients one could have expected these findings in our study. However, $15 \%$ of the patients had a fall leading up to admission with COVID-19. Falls in this acute setting are most likely an acute symptom of severe disease rather than an expression of chronic falling among frail individuals. In the Danish study by Karlsson et al., fall was registered in $8 \%$ of the $80+$-year-old patients [29]. Vrillon et al. found a higher fall incidence of $25 \%$ prior to 
Fig. 2 Receiver Operating Characteristic (ROC) curves illustrate the prediction of 90-day mortality using classification thresholds of Clinical Frailty Scale or Multidimensional Prognostic Index. Area under the ROC curves illustrates accuracy of the predictions

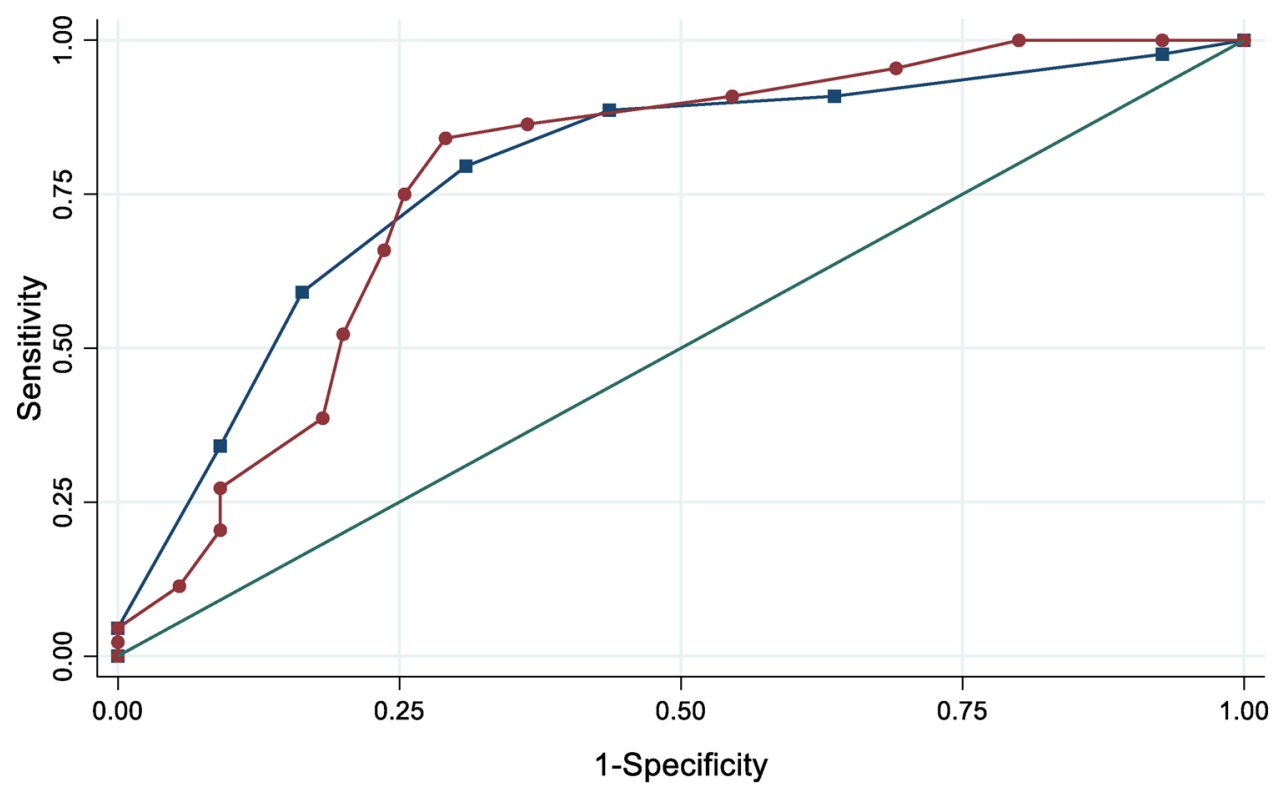

$\longrightarrow$ Clinical Frailty Scale [ROC area: 0.7851$]$

$\longrightarrow$ Multidimensional Prognostic Index [ROC area: 0.7769]
COVID-19-related hospitalisations of $85+$ years [30]. Looking into larger study populations in the future may provide more details about presence and importance of fall in older COVID-19 patients.

\section{The significance of frailty}

Our data indicate that front-line staff do pay more attention to decision on treatment level among frail older patients. Ideally, we believe that all patients should be involved in the decision of treatment level and it should be noted in the patient's health record when admitted with an acute condition. Continuous attention should be paid to this topic both in pandemics and beyond.

Not surprisingly, frail older patients with COVID-19 were found to have a more pronounced decline in functional level and a higher need of home care than the non-frail patients at discharge. More detailed knowledge about declining functional level and potential benefits of early in-hospital rehabilitation efforts is needed, as it has important socio-economic perspectives due to increased expenses. Concordant with our findings, a large multi-centre study found that frailty in COVID-19 patients has been associated with increased care needs at discharge in a large cohort study [37].

In a recent prospective study by Pilotto et al. using bedside MPI, they also found that older patients with COVID19 in MPI level 3 had a significant higher mortality rate than the patients in MPI level 1 [38]. Besides being a strong predictor of mortality in a Brazil cohort during the first COVID-19 wave, frailty assessment was found to provide extra prognostic information by capturing risk factors apart from known risk factors associated with age, co-morbidity and acute disease [39]. As in the study of Karlsson et al. [29] we found no association between confusion and death.

In the blood tests measured at admission, we only found one significant difference, where frail patients presented a lower hemoglobin than the non-frail. Few patients presented bleedings so our finding might be due to a more severe load of co-morbidity in the frail group which can lead to chronical anemia [34]. By analyzing the vital parameters at admission, we can only assume that a systolic blood pressure less than $140 \mathrm{mmHg}$ and a diastolic blood pressure less than $75 \mathrm{mmHg}$ were associated with 30-day mortality due to our small sample size. Nevertheless, emerging studies have demonstrated a high prevalence of hypertension among patients with COVID-19 [35]. At present, there is no clear epidemiological evidence supporting that hypertension itself is an independent risk factor for developing severe disease in patients with COVID-19 [36]. Therefore, these results must be examined in larger studies on frail older patients with COVID-19.

In our data, rMPI and CFS showed a fair and equal efficiency to predict 90-day mortality. Our rMPI accuracy in predicting 90-day mortality was as good as the bedside MPI in predicting in-hospital mortality in Pilotto's study [38]. Different settings may impact choice of frailty assessment tool as CFS takes a short time to complete, whereas bedside MPI is more time-consuming. Therefore, CFS might be more appropriately used in the ED screening patients for frailty [10], whereas completing a bedside MPI is valuable 
as a systematic application of CGA. MPI can be recommended to detangle complex physical and mental health needs among elderly and for early discharge planning in the geriatric wards.

\section{Strengths and limitations}

To our knowledge, this is the first study to evaluate change in functional status during hospitalization based on detailed data from EHRs and home care data from municipalities. We realize that since data were collected in the beginning of the pandemic with limited test resources, some frail older inpatients were not diagnosed with COVID-19 and therefore not included in the database. Due to an established public data warehouse, all admitted patients with known COVID19 disease are enrolled in the cohort. During the study period, efforts were made to bring patients with COVID-19 from nursing home $(\mathrm{NH})$ to hospitals to avoid contamination of cohabitants. The same preventive actions were applied among patients receiving home care. The hospitals in Central Denmark Region and in Denmark as a total did not reach a critical number of patients during the study period and it is not likely that any patients were kept out of hospital due to lack of capacity.

Our study has some important limitations that needs to be considered when interpreting the data. The record-based reviews were only performed by one reviewer per patient. However, in a recent study by Hansen et al., rMPI was found to have an acceptable inter-rater reliability and high agreement when compared to bedside-rated MPI [19]. In our study, none of the included hospitals have used standardized screening tools for delirium of whether the confusion was an expression of delirium. We based our assessment on EHR descriptions from receiving nurses and physicians notes and often the description was in agreement with clinical presentation of delirium. Also, despite lack of validation of the tool, we used changes in pre- and post-CFS scores and increased home care as a proxy intending to evaluate the potential functional decline during the hospital stay.

We did not account for differences in treatment across hospitals and departments, and also did not account for competing risk of death from other acute or chronical diseases with high mortality that might had led to admission in the first place. This might have introduced bias in our results although we have adjusted for gender and age.

Due to restriction on test kits in the beginning of the pandemic, only patients with relevant travel activity to pandemic areas and later only patients with classical symptoms like coughing and dyspnea were tested. Also, one can speculate if people living in a nursing home facility may more often have expressed a will about admission avoidance or restrictions to end-of-life care and therefore has not been admitted, but rather have received palliative care at home. This might have led to underdiagnoses of COVID-19 and therefore potentially limited entrance to this study.

Despite the confined number of patients included might restrict the conclusions that can be made based on our results, we believe that the focus on multidimensional frailty assessment is an important piece in the puzzle of COVID-19.

\section{Implications}

The included patients presented with a wide range of symptoms when admitted to the hospital. We only found minor differences in the clinical presentation of the disease when comparing frail older patients with non-frail, which is important knowledge when working with geriatric patients in the ED.

Our results suggest that COVID-19 in frail patients accelerate functional decline during hospitalization. This calls for further evaluation of impact of pre- and post-discharge rehabilitation. A large excess mortality among frail elderly with COVID-19 calls for both disease preventive actions like vaccinations and application of known hygienic precautions, and continuous improvement of treatment and care of frail older patients with COVID-19 both in-hospital and at home. A systematic use of frailty measurements will shed light on COVID-19 interaction with frailty domains and potentially improve patient-centered approaches.

Bedsides, MPI and standardized assessment of delirium among patients with COVID-19 infection are wanted to further investigate possible impacts of frailty on COVID-19 infection. Detailed knowledge about frailty status and frailty interactions with, e.g., co-morbidity enable the interdisciplinary team to closely monitor frailty domains like, e.g., functional status to identify specific interventions aimed to reduce negative health outcomes.

\section{Conclusion}

In older patients with COVID-19, it seems that frailty was associated with confusion at admission to hospital. Decision of treatment level about invasive ventilation and cardiopulmonary resuscitation was more prevalent among frail older patients than non-frail. Frail patients experienced more often a decline in physical functional abilities and had a higher risk of short-term mortality than non-frail patients. 


\section{Appendix 1}

Record-based multidimensional prognostic index (see Table 3).

Table 3 MPI items and applied data collection methods in the bedside- and record-based ratings

\begin{tabular}{|c|c|c|}
\hline MPI-item & Bedside rating data sources & Solution applied in the record-based rating \\
\hline C0-habitation & $\begin{array}{l}\text { Interviewing patients, relatives and/or home care staff } \\
\text { Medical audit }\end{array}$ & Medical record audit \\
\hline No. of drugs & $\begin{array}{l}\text { Drug chart review } \\
\text { Interviewing patients, relatives and/or home care staff } \\
\text { Medical record audit }\end{array}$ & $\begin{array}{l}\text { Medical record audit } \\
\text { Drug chart review } \\
\text { Clinical pharmacist notes }\end{array}$ \\
\hline FRS-ADL & $\begin{array}{l}\text { Physical examination } \\
\text { Clinical observation } \\
\text { Interviewing patients, relatives and/or home care staff } \\
\text { Medical record audit }\end{array}$ & $\begin{array}{l}\text { Medical record audit } \\
\text { Rated as self-sufficient if no information was available }\end{array}$ \\
\hline FRS-IADL & $\begin{array}{l}\text { Interviewing patients, relatives and/or home care staff } \\
\text { Clinical observation } \\
\text { Physical examination } \\
\text { Medical record audit }\end{array}$ & $\begin{array}{l}\text { Medical record audit } \\
\text { Rated as self-sufficient if no information was available }\end{array}$ \\
\hline SPMSQ & Structured interview (10-item questionnaire) & $\begin{array}{l}\text { Medical record audit } \\
\text { Rated as: } \\
\text { "Low" ( } 3 \text { points, score }=0) \text { if no cognitive impairment was described } \\
\text { "moderate" }(5 \text { points, score }=0.5) \text { if described as delirious } \\
\text { "High" }(10 \text { points, score }=1) \text { if diagnosed with dementia }\end{array}$ \\
\hline ESS & $\begin{array}{l}\text { Physical examination } \\
\text { Clinical observation } \\
\text { Interviewing patients, relatives and/or home care staff } \\
\text { Medical record audit }\end{array}$ & $\begin{array}{l}\text { Medical record audit } \\
\text { Rated as self-sufficient if no information was available }\end{array}$ \\
\hline CIRS-G & Medical record audit & Medical record audit \\
\hline MINA-SF & $\begin{array}{l}\text { Interviewing patients, relatives and/or home care staff } \\
\text { Physical examination } \\
\text { Clinical observation } \\
\text { Medical record audit }\end{array}$ & $\begin{array}{l}\text { Medical record audit } \\
\text { Neuropsychological prblems were rated: } \\
0 \text { points if the patients was diagnosed with dementia, moderate or } \\
\text { severe depression, or treated with anti-dementia drugs or antidepres- } \\
\text { sants } \\
1 \text { point if described mild cogniti ve impairment or mild depression } \\
2 \text { points if no cogniti ve or depressive symptoms were described } \\
\text { If no BMI available, BMI was rated: } \\
0 \text { points if described as underweight, malnouri shed, cachectic, suffer- } \\
\text { ing from sarcopenia or atrophy of the muscles } \\
1 \text { point if nutritional status was not described } \\
2 \text { points if described as of normal weight or well-nourished } \\
3 \text { points if described as overweight or obese }\end{array}$ \\
\hline
\end{tabular}

MPI-item: The Multidimensional Prognostic Index was an aggregate score based on the eight items

Co-habitation co-habitation status, No. of drugs number of drugs used at admission, FRS-ADL Functional Recovery Score Activities of Daily Living, FRS-IADL Functional Recovery Score Instrumentalized Activities of Daily Living, SPMSQ Short Portable Mental Status Questionnaire, ESS Exton Smith Scale, CIRS-G Cumulative Illness Rating Scale-Geriatrics, MNA-SF Mini Nutritional Assessment-Short Form; BMI: Body Mass Index $\left(\mathrm{kg} / \mathrm{m}^{2}\right)$ 


\section{Appendix 2}

See Fig. 3.

\section{Clinical Frailty Scale*}

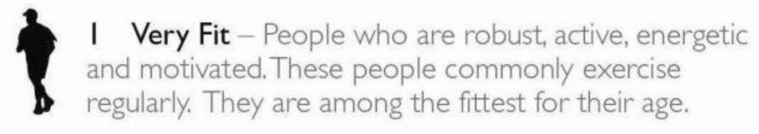

regularly. They are among the fittest for their age.

2 Well-People who have no active disease symptoms but are less fit than category 1. Often, they exercise or are very active occasionally, e.g. seasonally.

3 Managing Well - People whose medical problems are well controlled, but are not regularly active beyond routine walking.

4 Vulnerable - While not dependent on others for daily help, often symptoms limit activities. A common complaint is being "slowed up", and/or being tired during the day.

5 Mildly Frail - These people often have more evident slowing, and need help in high order IADLs (finances, transportation, heavy housework, medications). Typically, mild frailty progressively impairs shopping and walking outside alone, meal preparation and housework.

11 6 Moderately Frail - People need help with all outside activities and with keeping house. Inside, they often have problems with stairs and need help with bathing and might need minimal assistance (cuing, standby) with dressing.

Fig. 3 Clinical Frailty Scale, CFS

\section{Declarations}

Conflict of interest On behalf of all authors, the corresponding author states that there is no conflict of interest.

Ethical approval Due to national guidelines for quality improvement projects, no ethical approval was required from the local ethical committee (No: 1-10-72-1-20). EHR reviews were approved by all the hospital boards on the involved hospitals in Central Denmark Region.

\section{References}

1. Hewitt J, Carter B, Vilches-Moraga A, Quinn TJ, Braude P, Verduri A et al (2020) The effect of frailty on survival in patients with COVID-19 (COPE): a multicentre, European, observational cohort study. Lancet Public Health 5(8):e444-e451

2. De Smet R, Mellaerts B, Vandewinckele H, Lybeert P, Frans E, Ombelet $S$ et al (2020) Frailty and mortality in hospitalized
林 7 Severely Frail - Completely dependent for personal care, from whatever cause (physical or cognitive). Even so, they seem stable and not at high risk of dying (within $\sim 6$ months).

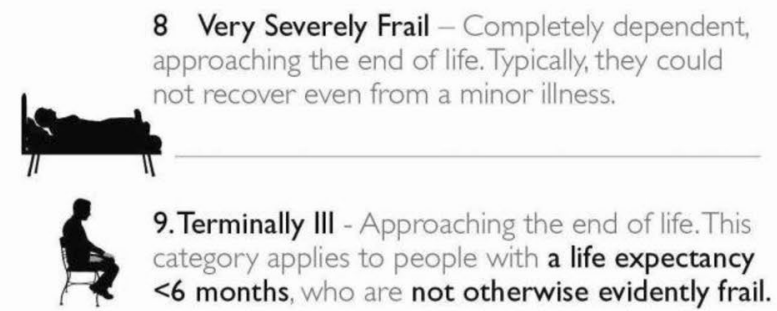

Scoring frailty in people with dementia

The degree of frailty corresponds to the degree of dementia. Common symptoms in mild dementia include forgetting the details of a recent event, though still remembering the event itself, repeating the same question/story and social withdrawal.

In moderate dementia, recent memory is very impaired, even though they seemingly can remember their past life events well.

They can do personal care with prompting.

In severe dementia they cannot do personal care without help.

* I. Canadian Study on Health \& Aging, Revised 2008.

2.K Rockwood et al.A global clinical measure of fitness and

frailty in elderly people. CMAJ 2005:173:489-495.

(1) 2009. Version 1.2_EN. All rights reserved, Geriatric Medicine Research, Dalhousie University, Halfiax, Canada, Permission granted to copy for research and educational purposes only.

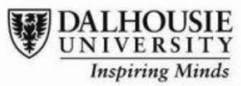

older adults with COVID-19: retrospective observational study. J Am Med Dir Assoc 21(7):928-932

3. Aw D, Woodrow L, Ogliari G, Harwood R (2020) Association of frailty with mortality in older inpatients with Covid-19: a cohort study. Age Ageing 49(6):915-922

4. Carter B, Collins JT, Barlow-Pay F, Rickard F, Bruce E, Verduri A et al (2020) Nosocomial COVID-19 infection: examining the risk of mortality The COPE-Nosocomial Study (COVID in Older PEople). J Hosp Infect 106(2):376-384

5. Bellelli G, Rebora P, Valsecchi MG, Bonfanti P, Citerio G (2020) Frailty index predicts poor outcome in COVID-19 patients. Intensive Care Med 46(8):1634-1636

6. Mendes A, Serratrice C, Herrmann FR, Genton L, Périvier S, Scheffler M et al (2020) Predictors of in-hospital mortality in older patients with covid-19: the COVID Age study. J Am Med Dir Assoc 21(11):1546-54.e3

7. Fiorentino M, Pentakota SR, Mosenthal AC, Glass NE (2020) The palliative performance scale predicts mortality in hospitalized patients with COVID-19. Palliat Med 34(9):1228-1234

8. Owen RK, Conroy SP, Taub N, Jones W, Bryden D, Pareek M et al (2020) Comparing associations between frailty and mortality in 
hospitalised older adults with or without COVID-19 infection: a retrospective observational study using electronic health records. Age Ageing. https://doi.org/10.1093/ageing/afaa167

9. Clegg A, Young J, Iliffe S, Rikkert MO, Rockwood K (2013) Frailty in elderly people. Lancet 381(9868):752-762

10. Dent E, Morley JE, Cruz-Jentoft AJ, Woodhouse L, RodríguezMañas L, Fried LP et al (2019) Physical frailty: icfsr international clinical practice guidelines for identification and management. $\mathbf{J}$ Nutr Health Aging 23(9):771-787

11 Burns GP, Lane ND, Tedd HM, Deutsch E, Douglas F, West SD et al (2020) Improved survival following ward-based non-invasive pressure support for severe hypoxia in a cohort of frail patients with COVID-19: Retrospective analysis from a UK teaching hospital. BMJ Open Respiratory Res 7(1):621. https://doi.org/10. 1136/bmjresp-2020-000621

12 Collins JT, Short R, Carter B, Verduri A, Myint PK, Quinn TJ et al (2020) The clinical frailty scale: estimating the prevalence of frailty in older patients hospitalised with COVID-19 the cope study. Geriatrics (Basel) 5(3):58. https://doi.org/10.3390/geria trics5030058

13. Ellis G, Gardner M, Tsiachristas A, Langhorne P, Burke O, Harwood RH et al (2017) Comprehensive geriatric assessment for older adults admitted to hospital. Cochrane Database Syst Rev. https://doi.org/10.1002/14651858.CD006211.pub3

14. Pilotto A, Ferrucci L, Franceschi M, D'Ambrosio LP, Scarcelli C, Cascavilla L et al (2008) Development and validation of a multidimensional prognostic index for one-year mortality from comprehensive geriatric assessment in hospitalized older patients. Rejuvenation Res 11(1):151-161

15. Gregersen M, Hansen TK, Jørgensen BB, Damsgaard EM (2020) Frailty is associated with hospital readmission in geriatric patients: a prognostic study. Eur Geriatr Med. https://doi.org/10. 1007/s41999-020-00335-w

16. Landi F, Barillaro C, Bellieni A, Brandi V, Carfì A, D'Angelo M et al (2020) The new challenge of geriatrics: saving frail older people from the SARS-COV-2 pandemic infection. J Nutr Health Aging 24(5):466-470

17. Docherty AB, Harrison EM, Green CA, Hardwick HE, Pius R, Norman L et al (2020) Features of 20133 UK patients in hospital with covid-19 using the ISARIC WHO clinical characterisation protocol: prospective observational cohort study. BMJ 369:m1985. https://doi.org/10.1136/bmj.m1985

18. Inouye SK, Studenski S, Tinetti ME, Kuchel GA (2007) Geriatric syndromes: clinical, research, and policy implications of a core geriatric concept. J Am Geriatr Soc 55(5):780-791

19. Hansen TK, Damsgaard EM, Shahla S, Bruun JM, Gregersen M (2020) A reliable and record-based frailty assessment method for older medical inpatients. Eur Geriatr Med 11(5):803-812

20. Statistics Denmark (2020) https://www.dst.dk/en/OmDS. (Accessed 19 Jan 2020).

21. Schmidt M, Pedersen L, Sørensen HT (2014) The danish civil registration system as a tool in epidemiology. Eur J Epidemiol 29(8):541-549

22. Region BICD. Central Denmark Region. (2021) https://www.rm. $\mathrm{dk} /$ om-os/organisation/it/business-intelligence (Accessed 19 Jan 2021).

23. Harris PA (2009) Research electronic data capture (REDCap) - A metadata-driven methodology and workflow process for providing translational research informatics support. J Biomed Inform 42(2):377-381

24. Hansen TK, Shahla S, Damsgaard EM, Bossen SRL, Bruun JM, Gregersen M (2021) Mortality and readmission risk can be predicted by the record-based multidimensional prognostic index: a cohort study of medical inpatients older than 75 years. Eur Geriat Med. https://doi.org/10.1007/s41999-021-00453-Z
25. Rockwood K, Song X, MacKnight C, Bergman H, Hogan DB, McDowell I et al (2005) A global clinical measure of fitness and frailty in elderly people. CMAJ 173(5):489-495

26. StataCorp (2019) Stata statistical software release 16. StataCorp LCC

27. Kennedy M, Helfand BKI, Gou RY, Gartaganis SL, Webb M, Moccia JM et al (2020) Delirium in older patients with COVID19 presenting to the emergency department. JAMA Netw Open 3(11):e2029540. https://doi.org/10.1001/jamanetworkopen.2020. 29540

28. Marengoni A, Zucchelli A, Grande G, Fratiglioni L, Rizzuto D (2020) The impact of delirium on outcomes for older adults hospitalised with COVID-19. Age Ageing 49(6):923-926

29. Karlsson LK, Jakobsen LH, Hollensberg L, Ryg J, Midttun M, Frederiksen $\mathrm{H}$ et al (2020) Clinical presentation and mortality in hospitalized patients aged 80+ years with COVID-19-A retrospective cohort study. Arch Gerontol Geriatr 94:104335. https://doi. org/10.1016/j.archger.2020.104335

30. Vrillon A, Hourregue C, Azuar J, Grosset L, Boutelier A, Tan $S$ et al (2020) COVID-19 in older adults: a series of 76 patients aged 85 years and older with COVID-19. J Am Geriatr Soc 68(12):2735-2743

31. Garcez FB, Aliberti MJR, Poco PCE, Hiratsuka M, Takahashi SF, Coelho VA et al (2020) Delirium and adverse outcomes in hospitalized patients with COVID-19. J Am Geriatr Soc 68(11):2440-2446

32. Davis DHJ, Muniz-Terrera G, Keage HAD, Stephan BCM, Fleming J, Ince PG et al (2017) Association of delirium with cognitive decline in late life: a neuropathologic study of 3 population-based cohort studies. JAMA Psychiat 74(3):244-251

33. Liu W, Tao ZW, Wang L, Yuan ML, Liu K, Zhou L et al (2020) Analysis of factors associated with disease outcomes in hospitalized patients with 2019 novel coronavirus disease. Chin Med J (Engl) 133(9):1032-1038

34. Zarychanski R, Houston DS (2008) Clinical paradigms - Anemia of chronic disease: a harmful disorder or an adaptive, beneficial response? CMAJ 179(4):333-337

35. Zhou F, Yu T, Du R, Fan G, Liu Y, Liu Z et al (2020) Clinical course and risk factors for mortality of adult inpatients with COVID-19 in Wuhan, China: a retrospective cohort study. Lancet 395(10229): 1054-1062

36. Shibata S, Arima H, Asayama K, Hoshide S, Ichihara A, Ishimitsu $T$ et al (2020) Hypertension and related diseases in the era of COVID-19: a report from the Japanese Society of Hypertension Task Force on COVID-19. Hyper Res 43(10):1028-1046

37 Welch C (2021) Age and frailty are independently associated with increased COVID-19 mortality and increased care needs in survivors: results of an international multi-centre study. Age Ageing. https://doi.org/10.1093/ageing/afab026

38. Pilotto A, Azzini M, Cella A, Cenderello G, Castagna A, Pilotto A et al (2021) The multidimensional prognostic index (MPI) for the prognostic stratification of older inpatients with COVID-19: a multicenter prospective observational cohort study. Arch Gerontol Geriatr 95:104415. https://doi.org/10.1016/j.archger.2021.104415

39. Aliberti MJR, Szlejf C, Avelino-Silva V, Suemoto CK, Apolinario D, Dias MB et al (2021) COVID-19 is not over and age is not enough: Using frailty for prognostication in hospitalized patients. J Am Geriat Soc. https://doi.org/10.1111/jgs.17146

Publisher's Note Springer Nature remains neutral with regard to jurisdictional claims in published maps and institutional affiliations. 